\title{
Research Paper: Physical Rehabilitation Accessibility Assessment Questionnaire for People With Physical Disability: A Development and Validation Study in Iran
}

\author{
Marzieh Shirazikhah' $^{1}$ (D), Arash Mirabzadeh ${ }^{2}$ (D), Homeira Sajjadi ${ }^{3}$, Mohammad Taghi Joghataei ${ }^{4}$ (D), Akbar Biglarian 5 (D), Farahnaz Mohammadi \\ Shahboulaghi $^{6^{*}}$ (D), Hamid Sharif $\mathrm{Nia}^{7}$ (D), Zahra Jorjoran Shushtari ${ }^{1}$ (D) \\ 1. Social Determinants of Health Research Center, University of Social Welfare and Rehabilitation Sciences, Tehran, Iran. \\ 2. Department of Psychiatry, Social Determinants of Health Research Center, University of Social Welfare and Rehabilitation Sciences, Tehran, Iran. \\ 3. Social Welfare Management Research Center, University of Social Welfare and Rehabilitation Sciences, Tehran, Iran. \\ 4. Department of Anatomy and Neuroscience, Neuroanatomy and Neuroscience, Cellular and Molecular Research Center, School of Medicine, Iran Medical \\ University, Tehran, Iran. \\ 5. Department of Biostatistics, School of Rehabilitation Sciences, University of Social Welfare and Rehabilitation Sciences, Tehran, Iran. \\ 6. Department of Nursing, Social Determinants of Health Research Center, University of Social Welfare and Rehabilitation Sciences, Tehran, Iran \\ 7. Department of Nursing, School of Nursing and Midwifery, Mazandaran University of Medical Science, Sari, Iran.
}

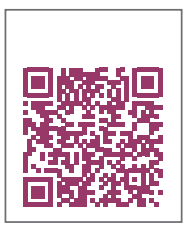

Cftation: Shirazikhah M, Mirabzadeh A, Sajjadi H, Joghataei MT, Biglarian A, Mohammadi Shahboulaghi F, et al. Physical Rehabilitation Accessibility Assessment Questionnaire for People With Physical Disability: A Development and Validation Study in Iran. Iranian Rehabilitation Journal. 2020; 18(2):211-222. http://dx.doi.org/10.32598/irj.18.2.941.1

Article info:

Received: 01 Oct 2019

Accepted: 27 Nov 2019

Available Online: 01 Jun 2020

\section{Keywords:}

Disability, Confirmatory factor analysis, Psychometrics,

Reliability, Validity,

Accessibility, Rehabilitation

\section{A B S T RACT}

Objectives: The primary focus in the rehabilitation services program is the universal coverage of these services, in other words, to provide better access to these services in any place and situation. The present study aimed to develop and validate a physical rehabilitation accessibility assessment questionnaire as a standardized instrument that can be adaptable to people with physical disabilities.

Methods: An exploratory sequential mixed methods design was used to develop and validate this questionnaire. Appropriate content was prepared through the literature review, related studies analysis, and focus group discussions with a qualitative approach. Then, the face, content, and construct validity and reliability of the questionnaire were evaluated.

Results: The physical rehabilitation accessibility questionnaire with 17 items was formulated, and its psychometric properties were evaluated through testing in a study sample of 200 people with disabilities who filled up the questionnaire. Exploratory factor analysis indicated that $81 \%$ of the variance of the accessibility to physical rehabilitation services was determined by four factors of affordability, transport, social support, and information access. Indices of $\mathrm{PCFI}=0.772, \mathrm{PNFI}=0.717, \mathrm{NFI}=0.877, \mathrm{CFI}=0.952, \mathrm{CMIN} / \mathrm{DF}=1.867, \mathrm{RMSEA}=0.066$, and $\mathrm{AGFI}=0.871$ confirmed the fitness of the final model. The convergent and divergent validity and reliability of the questionnaire were also confirmed.

Discussion: The questionnaire has an appropriate psychometric property that makes it useful for assessing the accessibility of physical rehabilitation services for people with physical disabilities. This questionnaire can be used in subsequent studies to measure the accessibility of rehabilitation services.

* Corresponding Author:

Farahnaz Mohammadi Shahboulaghi, PhD.

Address: Department of Nursing, Social Determinants of Health Research Center, University of Social Welfare and Rehabilitation Sciences, Tehran, Iran. Tel: +98 (21) 222180008

E-mail:jorjoran.z@gmail.com 


\section{Highlights}

- The Persian version of the physical rehabilitation accessibility assessment questionnaire has an appropriate development and validation.

- The Persian version of the physical rehabilitation accessibility assessment questionnaire is one of the key tools for evaluating the accessibility of people with disabilities to physical rehabilitation services.

- Local and foreign researchers can use the Persian version of the physical rehabilitation accessibility assessment questionnaire for assessing the accessibility of health services.

\section{Plain Language Summary}

This study was conducted to develop and validate a local questionnaire. This questionnaire can be useful for assessing the accessibility of health services by local and foreign researchers. Also, this questionnaire can provide policymakers, executive directors, therapists, and researchers with important insights into and accurate information on the accessibility of physical rehabilitation services for people with disabilities and enable them to develop effective intervention programs.

\section{Introduction}

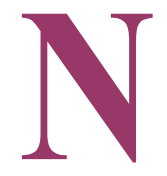

owadays, with the increasing number of the elderly population and chronic diseases, the incidence of disability has also increased. According to the World Health Organization (WHO) report, 1 billion or $15 \%$ of the world's population suffer from disabilities; accordingly, more than 11 million of the Iranian population have disabilities and need rehabilitation services $[1,2]$.

The WHO suggests that people with disabilities are twice more likely to seek access to health services and 50\% of people with disabilities cannot afford to pay for health care, and thereby facing catastrophic health care expenditures in comparison with the healthy individuals $[3,4]$.

Another important issue in health service planning is providing widespread coverage of healthcare services. All people with disabilities should have access to rehabilitation services [1]. Accessibility refers to both physical access (accessibility of facilities, equipment, and information) and economic access (accessibility of services, products, and technologies) [5]. Limited access to rehabilitation services can exacerbate the consequences of illness or injury, cause activity limitations and participation restrictions, and increase the costs of treatment and rehabilitation for people with disabilities, ultimately imposing a negative effect on their quality of life [6].

Several studies have been reviewed to identify appropriate parameters that deserve to be included in the sur- vey. In previous studies, the accessibility and availability of rehabilitation services were measured using various indices such as insurance coverage and the amount of subsidy [7], waiting time [8], and distance/proximity to the center for rehabilitation services $[9,10]$.

According to the literature review, no comprehensive tool is available for assessing the accessibility to rehabilitation services for people with disabilities. The availability of a reliable tool in this area is not only limited to the identification of the causes and the contributing factors of inaccessibility to useful services but also that of the ability to access rehabilitation services. Thus, providing necessary evidence and proper information can improve the awareness and precision of the decision-makers in this field [11]. To address this gap in both rehabilitation settings and research, this study has developed and validated a physical rehabilitation accessibility assessment questionnaire to assess the accessibility of rehabilitation services for people with disabilities.

\section{Methods}

This study was conducted using the exploratory sequential mixed methods (i.e. qualitative and quantitative) approach in three phases: 1 . Preparing appropriate content and formulating the questionnaire through literature review and focus group discussions; 2. Assessing validity indices; 3 . Evaluating the reliability of the questionnaire in a pilot study; and 4. Conducting exploratory factor analysis. 


\section{Phase 1: Appropriate content preparation}

\section{Literature review}

Based on the standard methods for the development of questionnaires [12], all related studies on the assessment of access to health and rehabilitation services were searched to find the existing instruments and items. In this regard, several keywords, namely, "Health Service", "Healthcare", "Services", "Services, Health", "Services, care", "Rehabilitation", and "Accessibility", were searched in the following databases: Iranmedex, SID, Irandoc, Magiran, PubMed/Medline, and Scopus. Google scholar, as an academic search engine, was also searched. The inclusion criteria were as follows: articles related to the accessibility of rehabilitation services, papers published between 2000 and 2017, and papers available as full text.

First, the titles and abstracts of the articles were assessed to ensure both relevance to the subject matter and publication date. Then, the studies were investigated respecting full-text availability. In the final step of the review, the selected articles that met the inclusion criteria were entered in the content analysis. We employed the content analysis for extracting the related content from the selected articles. The included articles were studied several times, and the meaning units were coded through content analysis. Afterward, the extracted codes, categories, and subcategories were considered for item generation and questionnaire development.

\section{Focus group discussions}

In this step, the findings of the literature review were shared with the experts through four Focus Group Discussions (FGDs). Participants in the FGDs comprised three rehabilitation specialists (a physiotherapist, an occupational therapist, and a speech therapist), one psychiatrist, two community physicians, one nurse, one statistician, and two people with disabilities as lay experts. Each session lasted two hours and ended until no further issue needed to be discussed. The data gathering continued until the data saturation was achieved. The recorded texts were written and reread several times. The texts were analyzed using the content analysis method. At the end of this phase of the study, based on the qualitative data and the literature review, primary items of the questionnaire were generated, and the questionnaire was formulated.

\section{Phase 2: Validity of the questionnaire}

Using the results of the literature review and the FGDs, the initial version of the questionnaire was prepared. Then, the face, content, and construct (i.e. convergent and divergent) validities were measured to assess the overall validity of the questionnaire. The study population was conveniently selected from the Disability Policy Consortium (DPC). The inclusion criteria were having a physical disability for a maximum of one year and were willing to participate in the study. The exclusion criterion was having an intellectual disability. The number of eligible participants in the study was 250 , but only 200 persons expressed willingness to participate in the study (Table 1). Since the sample size of at least 50-100 participants is considered acceptable $[12,13]$, then 200 questionnaires were distributed, and data were collected through the census.

\section{Face validity}

At this step, a first draft of the questionnaire, which comprised the items reflecting the literature review and the FGDs, was given to ten persons with physical disabilities. The participants were selected from the DPC using a convenience sampling method. The inclusion criteria were having a physical disability for a maximum of one year and willing to participate in the study. People with intellectual disabilities were excluded from the study. After explaining the study objectives, they were asked about the quality of the questionnaire, and which question failed to have sufficient simplicity and clarity. Finally, they were requested to express their suggestions for those questions.

\section{Content validity}

For assessing the content validity of the questionnaire, two main indices, including content Validity Ratio (CVR) and Content Validity Index (CVI) were measured (Table 2). To determine the CVR and CVI, a first draft of the questionnaire, a cover letter expressly delineating the objectives of the study, the definition of the accessibility to physical rehabilitation services and that of the content validity indices, and the indications for rating the questions, along with the response form were sent to 15 rehabilitation specialists, i.e. speech therapists, physiotherapists, and expert analysts, who had experience in the development and validation of the questionnaire. The experts were asked to give their opinions on whether each question is essential, useful, or relevant to measure the construct under study based on a 3-point Likert scale (1: Essential; 2: Useful but not essential; and 3: Unes- 
sential). As suggested by Lawshe (1975), based on "established psychophysical principles", a level of 50\% agreement gives some assurance of content validity [14].

To measure the CVI, the experts in the relevant fields were asked to determine the relevance, simplicity, and clarity of each item of the questionnaire based on a 4-point Likert-type scale recommended by Polit and Beck [15].

\section{Phase 3: Reliability of the questionnaire}

After assessing the face and content validities of the questionnaire, a pilot study was conducted on 30 people with disabilities, who were willing to participate in the study.

Phase 4: Exploratory factor analysis
The draft of the questionnaire was evaluated using exploratory factor analysis with a large sample of participants $(n=200)$. The participants were recruited by a purposeful sampling method. The inclusion criteria were having a physical disability for a maximum of one year and willing to participate in the study. In the first step of the exploratory factor analysis, the Kaiser-Meyer-Olkin measure of sampling adequacy and Bartlett's test were calculated. Then, the hidden factors were extracted using the maximum likelihood estimation and the varimax rotation as well as the gravel graph via SPSS V. 22. The presence of a single item in the factor based on the formula $C V=5.152 \div \sqrt{ }(n-2)[16]$ was estimated to be approximately 0.3 (in this formula, $\mathrm{CV}$ is the number of extractable factors, and $\mathrm{n}$ is the sample size of the study)

Table 1. Demographical characteristics of the study participants $(N=200)$

\begin{tabular}{|c|c|c|}
\hline \multicolumn{2}{|c|}{ Variables } & \multirow{2}{*}{$\frac{\text { No. (\%) }}{13(6.5)}$} \\
\hline \multirow{3}{*}{ Age (y) } & $0-18$ & \\
\hline & $19-59$ & $174(87)$ \\
\hline & $>60$ & $13(6.5)$ \\
\hline \multirow{2}{*}{ Gender } & Female & $117(58.5)$ \\
\hline & Male & $83(41.5)$ \\
\hline \multirow{3}{*}{ Levels of disability } & Mild & $20(10)$ \\
\hline & Moderate & $57(28.5)$ \\
\hline & Severe & $123(61.5)$ \\
\hline \multirow{5}{*}{ Marital status } & Single & $119(59.5$ \\
\hline & Married & 68 (34) \\
\hline & Widow & $2(1)$ \\
\hline & Separated & $5(2.5)$ \\
\hline & Divorced & $6(2)$ \\
\hline \multirow{5}{*}{ Employment } & Employed & $55(22)$ \\
\hline & Student & $15(7.5)$ \\
\hline & Housewife & $40(20)$ \\
\hline & Retired & $12(6)$ \\
\hline & Unemployed & $88(44)$ \\
\hline \multirow{5}{*}{ Social class } & Lower class & $6(3)$ \\
\hline & Lower middle class & $97(48.5)$ \\
\hline & Middle class & $79(39.5)$ \\
\hline & Upper middle class & $9(4.5)$ \\
\hline & Upper class & $9(4.5)$ \\
\hline \multirow{5}{*}{ Educational Status } & Illiterate & $9(4.5)$ \\
\hline & Elementary school & $21(10.5)$ \\
\hline & High school & $94(47)$ \\
\hline & Diploma & $74(37)$ \\
\hline & University & $2(1)$ \\
\hline
\end{tabular}


Table 2. Content validity indices of accessibility to physical rehabilitation services

\begin{tabular}{|c|c|c|c|c|c|}
\hline No. & Items & CVR & True/False & I-CVI & True/False \\
\hline 1 & $\begin{array}{l}\text { How much reliable sources of information (the Internet, mass me- } \\
\text { dia, social networks) are accessible to you once you are in need to } \\
\text { receive information regarding rehabilitation services? }\end{array}$ & 0.60 & True & 1.00 & True \\
\hline 2 & $\begin{array}{l}\text { How much information regarding rehabilitation services has been } \\
\text { provided to you by the rehabilitation therapists? }\end{array}$ & 0.87 & True & 0.92 & True \\
\hline 3 & $\begin{array}{l}\text { How much enough information has been provided to you by guide- } \\
\text { lines, posters, and pamphlets when referring to the rehabilitation } \\
\text { center? }\end{array}$ & 0.73 & True & 0.92 & True \\
\hline 4 & $\begin{array}{l}\text { How much have you been deprived of receiving rehabilitation ser- } \\
\text { vices due to the long time needed to reach the center? }\end{array}$ & 0.73 & True & 0.92 & True \\
\hline 5 & $\begin{array}{l}\text { How much have you been deprived of receiving rehabilitation ser- } \\
\text { vices because of your home away from the center? }\end{array}$ & 0.60 & True & 0.92 & True \\
\hline 6 & $\begin{array}{l}\text { How much do you have to get rehabilitation services at a center far } \\
\text { away from your place of residence? }\end{array}$ & 0.73 & True & 0.92 & True \\
\hline 7 & $\begin{array}{l}\text { How often do you receive rehabilitation services from distant cen- } \\
\text { ters far away from your place of living? }\end{array}$ & 0.20 & False & 0.83 & True \\
\hline 8 & $\begin{array}{l}\text { How much have you used each of the following items to go to the } \\
\text { rehabilitation center? } \\
\text { Taxicab } \\
\text { Personal vehicle } \\
\text { Family vehicle } \\
\text { Public transportation } \\
\text { On foot } \\
\text { Fitted vehicles } \\
\text { Other }\end{array}$ & 0.47 & False & 1.00 & True \\
\hline 9 & $\begin{array}{l}\text { How much have you been deprived of rehabilitation services due to } \\
\text { the lack of a suitable vehicle? }\end{array}$ & 0.73 & True & 0.92 & True \\
\hline 10 & $\begin{array}{l}\text { How much does the center of origin provide patients with an ap- } \\
\text { propriate vehicle if they are needed to be referred to another rehab } \\
\text { center? }\end{array}$ & 0.20 & False & 0.75 & False \\
\hline 11 & $\begin{array}{l}\text { How often the vehicle fit for your disability is available for your } \\
\text { transfer to the rehabilitation center? }\end{array}$ & 0.47 & False & 0.92 & True \\
\hline 12 & $\begin{array}{l}\text { How many times have you canceled your rehabilitation services ap- } \\
\text { pointment because of the long waiting time? }\end{array}$ & 0.73 & True & 0.92 & True \\
\hline 13 & $\begin{array}{l}\text { How much was an unfit route to the rehabilitation center a reason } \\
\text { for your denial of rehabilitation services? }\end{array}$ & 0.60 & True & 1.00 & True \\
\hline 14 & $\begin{array}{l}\text { How much have you been deprived of receiving rehabilitation ser- } \\
\text { vices due to the unfit route of transport? }\end{array}$ & 0.33 & False & 1.00 & True \\
\hline 15 & $\begin{array}{l}\text { How much is the assistive device (crutches, wheelchairs, walkers, } \\
\text { etc.) a reason for not using your rehabilitation services? }\end{array}$ & 0.20 & False & 1.00 & True \\
\hline 16 & $\begin{array}{l}\text { How many times have you canceled your rehabilitation services ap- } \\
\text { pointment because of the long waiting time? }\end{array}$ & 0.60 & True & 1.00 & True \\
\hline 17 & $\begin{array}{l}\text { How much have you been deprived of rehabilitation services due to } \\
\text { the bureaucratic process in rehabilitation services? }\end{array}$ & 0.60 & True & 0.92 & True \\
\hline 18 & How much have your therapists referred you to other therapists? & 0.07 & False & 0.83 & True \\
\hline 19 & How effective was the referral result? & -0.20 & False & 0.67 & False \\
\hline 20 & Has the referral provided you with appropriate services? & -0.33 & False & 0.50 & False \\
\hline 21 & $\begin{array}{l}\text { How much have you been deprived of receiving rehabilitation ser- } \\
\text { vices because you could not afford to pay their costs? }\end{array}$ & 1.00 & True & 0.92 & True \\
\hline 22 & $\begin{array}{l}\text { How many times have you been deprived of rehabilitation services } \\
\text { due to the inability to pay for your transportation? }\end{array}$ & 0.47 & False & 1.00 & True \\
\hline 23 & How much do you have to get expensive rehabilitation services? & 0.33 & False & 0.83 & True \\
\hline 24 & $\begin{array}{l}\text { How many times have you been deprived of rehabilitation services } \\
\text { because you could not afford to pay for the drug? }\end{array}$ & 0.07 & False & 0.92 & True \\
\hline
\end{tabular}




\begin{tabular}{|c|c|c|c|c|c|}
\hline No. & Items & CVR & True/False & I-CVI & True/False \\
\hline 25 & $\begin{array}{l}\text { How many times have you been deprived of rehabilitation services } \\
\text { because you could not afford to pay the cost of rehabilitation aids } \\
\text { (hearing aids, eyeglasses, crutches, wheelchair, walker, etc.)? }\end{array}$ & 0.47 & False & 1.00 & True \\
\hline 26 & $\begin{array}{l}\text { How much have the welfare organizations paid your costs of reha- } \\
\text { bilitation services? }\end{array}$ & 0.73 & True & 1.00 & True \\
\hline 27 & $\begin{array}{l}\text { How much have you been deprived of receiving rehabilitation ser- } \\
\text { vices due to a lack of insurance? }\end{array}$ & 1.00 & True & 1.00 & True \\
\hline 28 & $\begin{array}{l}\text { How much of the service you have needed was covered by insur- } \\
\text { ance? }\end{array}$ & 0.47 & False & 0.92 & True \\
\hline 29 & $\begin{array}{l}\text { How much does your basic health insurance cover your rehabilita- } \\
\text { tion services? }\end{array}$ & 0.47 & False & 1.00 & True \\
\hline 30 & How much does your private health insurance cover? & 0.60 & True & 1.00 & True \\
\hline 31 & How much does your work cover your rehabilitation services? & 0.47 & False & 0.92 & True \\
\hline 32 & $\begin{array}{l}\text { How much have you been deprived of rehabilitation services due to } \\
\text { the lack of family and friends' support for your transport from home } \\
\text { to a rehabilitation facility? }\end{array}$ & 0.47 & False & 0.92 & True \\
\hline 33 & $\begin{array}{l}\text { How much have you been deprived of rehabilitation services due to } \\
\text { the lack of accompanying family and friends? }\end{array}$ & 0.33 & False & 0.92 & True \\
\hline 34 & $\begin{array}{l}\text { How much have you been deprived of rehabilitation services due to } \\
\text { the lack of financial support from family and friends? }\end{array}$ & 0.60 & True & 0.92 & True \\
\hline
\end{tabular}

[17]. According to the 3-indicator rule, at least three indicators should be for each factor [18].

\section{Statistical analysis}

The kappa coefficient was used to determine the interrater agreement on the validation of the questionnaire. Accordingly, the scores greater than 0.75 , between 0.60 and 0.75 , and lower than 0.60 were considered as excellent, good, and weak inter-rater agreement, respectively [15].

The CVR index for each item in our study was interpreted based on the minimum values suggested by Lawshe Table (1975). As we had 15 experts, a score of $\geq 50 \%$ for each item indicated the essentiality and importance of that item in the questionnaire. For the item content validity index (I-CVI), values greater than 0.79 , between 0.70 and 0.79 , and lower than 0.70 were considered appropriate, questionable, and unacceptable (i.e. that item should be removed), respectively. The scale content validity index (S-CVI) was calculated based on the average method (S-CVI/Ave) [7]. Polit and Beck have suggested a score equal to or greater than $90 \%$ as an acceptable S-CVI/Ave [8].

The Cronbach alpha, McDonald's Omega, and Theta alpha coefficients were estimated to assess the internal consistency of the accessibility of physical rehabilitation services questionnaire [19] (Table 3). The internal consistency of the questionnaire was considered to be more than 0.7 [20]. Finally, the stability of the instruments was calculated [15]. The stability of the instruments or the stability of some kind of alternatives for the Cronbach alpha coefficient in the analysis of the structural equation model was more than 7.0, which is acceptable [21].

The univariate and multivariate distribution of data was analyzed for pertinent data. The existence of multivariate data was evaluated using Mahalanobis D-squared statistics $(\mathrm{P}<0.001)$ while multivariate kurtosis was investigated using the Mardia coefficient (>8) [21]. The percentage of missing data was evaluated using multiple imputations, and then the missing values were replaced by the mean score. The data were analyzed by SPSS V. 14.

\section{Results}

\section{Phase 1: Appropriate content preparation}

\section{Literature review}

In the initial search, 359 papers were identified, of which, 256 papers were chosen for the abstract review. Then, 110 articles that met the mentioned inclusion criterion remained for the full-text review. Afterward, 62 articles were excluded due to the inaccessibility of full text, and 36 articles were eliminated due to the lack of consistency with the aim of the study. Finally, 12 articles that met all the inclusion criteria were selected and used for the content analysis. 
Table 3. Factor analysis of the accessibility to rehabilitation services questionnaire

\begin{tabular}{|c|c|c|c|c|c|}
\hline Factors & Items & Loading & $h_{2}$ & $\begin{array}{l}\text { Variance } \\
\text { (\%) }\end{array}$ & $\begin{array}{l}\text { Eigenval- } \\
\text { ues }\end{array}$ \\
\hline \multirow{8}{*}{ 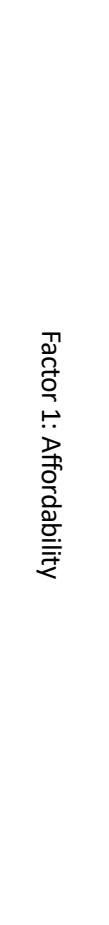 } & $\begin{array}{l}\text { Q16- How many times have you been deprived of rehabilitation } \\
\text { services because you could not afford to pay for the drug? }\end{array}$ & 0.939 & 0.423 & \multirow{8}{*}{31.194} & \multirow{8}{*}{5.615} \\
\hline & $\begin{array}{l}\text { Q17- How many times have you been deprived of rehabilitation ser- } \\
\text { vices because you could not afford to pay the cost of rehabilitation } \\
\text { aids (hearing aids, eyeglasses, crutches, wheelchair, walker, etc.)? }\end{array}$ & 0.830 & 0.700 & & \\
\hline & $\begin{array}{l}\text { Q15- How many times have you been deprived of rehabilitation } \\
\text { services due to inability to pay for your transportation? }\end{array}$ & 0.825 & 0.706 & & \\
\hline & $\begin{array}{l}\text { Q14- How much have you been deprived of receiving rehabilitation } \\
\text { services because you could not afford to pay their costs? }\end{array}$ & 0.709 & 0.700 & & \\
\hline & $\begin{array}{l}\text { Q13- How much have you been deprived of rehabilitation services } \\
\text { due to the bureaucratic process in rehabilitation services? }\end{array}$ & 0.658 & 0.501 & & \\
\hline & $\begin{array}{l}\text { Q12- How many times have you canceled your rehabilitation ser- } \\
\text { vices appointment because of the long waiting time? }\end{array}$ & 0.598 & 0.423 & & \\
\hline & $\begin{array}{l}\text { Q9- How much have you been deprived of rehabilitation services } \\
\text { because of your late arrival for the appointment? }\end{array}$ & 0.571 & 0.386 & & \\
\hline & $\begin{array}{l}\text { Q10- How much have you been deprived of rehabilitation services } \\
\text { due to the lack of space adaptation for the disabled in the rehabili- } \\
\text { tation facility and passageway? }\end{array}$ & 0.302 & 0.365 & & \\
\hline \multirow{3}{*}{ 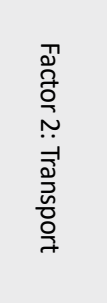 } & $\begin{array}{l}\text { Q5- How much are you compelled to seek these services because } \\
\text { most centers are far from your home? }\end{array}$ & 0.833 & 0.575 & \multirow{3}{*}{20.183} & \multirow{3}{*}{30.633} \\
\hline & $\begin{array}{l}\text { Q4- How much have you been deprived of rehabilitation services } \\
\text { because of the lack of access to these services in your area? }\end{array}$ & 0.820 & 0.657 & & \\
\hline & $\begin{array}{l}\text { Q6- How much have you been deprived of rehabilitation services } \\
\text { due to the lack of transportation facilities? }\end{array}$ & 0.613 & 0.598 & & \\
\hline \multirow{3}{*}{ 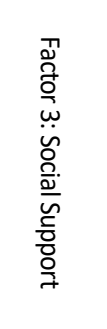 } & $\begin{array}{l}\text { Q24-How much have you been deprived of rehabilitation services } \\
\text { due to the lack of financial support from family and friends? }\end{array}$ & 0.917 & 0.772 & \multirow{3}{*}{21.322} & \multirow{3}{*}{3.838} \\
\hline & $\begin{array}{l}\text { Q23-How much have you been deprived of rehabilitation services } \\
\text { due to the lack of support for your transport from home to a reha- } \\
\text { bilitation facility and vice versa? }\end{array}$ & 0.757 & 0.590 & & \\
\hline & $\begin{array}{l}\text { Q19-How much have you been deprived of receiving rehabilitation } \\
\text { services due to lack of insurance? }\end{array}$ & 0.303 & 0.219 & & \\
\hline \multirow{3}{*}{ 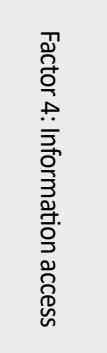 } & $\begin{array}{l}\text { Q2-How much information regarding rehabilitation services has } \\
\text { been provided to you by the rehabilitation therapists? }\end{array}$ & 0.891 & 0.783 & \multirow{3}{*}{8.333} & \multirow{3}{*}{1.500} \\
\hline & $\begin{array}{l}\text { Q1- How much reliable sources of information (the Internet, mass } \\
\text { media, social networking) are accessible to you once you are in } \\
\text { need to receive information regarding rehabilitation services? }\end{array}$ & 0.590 & 0.361 & & \\
\hline & $\begin{array}{l}\text { Q3- How much information needed have you obtained from guide- } \\
\text { lines, posters, and pamphlets when referring to the rehabilitation } \\
\text { center? }\end{array}$ & 0.474 & 0.235 & & \\
\hline
\end{tabular}

Mranian Rehabilitation Dourna 
Table 4. Construct validity and reliability results and the Fornell-Larcker criterion

\begin{tabular}{ccccccccc}
\hline Factors & $\boldsymbol{\alpha}$ & $\boldsymbol{\theta}$ & $\boldsymbol{\Omega}$ & $\mathbf{C R}$ & AVE & MSV & ASV \\
\hline Affordability & 0.864 & 0.924 & 0.724 & 0.892 & 0.513 & 0.406 & 0.399 \\
Transport & 0.801 & 1.087 & 0.834 & 0.751 & 0.515 & 0.406 & 0.311 \\
Social support & 0.791 & 1.11 & 0.77 & 0.801 & 0.575 & 0.393 & 0.305 \\
Information access & 0.79 & 1.1 & 0.75 & 0.8 & 0.54 & 0.373 & 0.301 \\
\hline
\end{tabular}

a: Cronbach alpha coefficient; $\theta$ : Theta coefficient; $\Omega$ : McDonald's Omega coefficient; CR: Construct Reliability; AVE: Average Variance Extracted; MSV: Maximum Shared Squared Variance; ASV: Average Shared Squared Variance

\section{Focus group discussions}

In this step, feedbacks of the experts on the accessibility of physical rehabilitation services definition, dimensions, and obstacles for people with disabilities were collected through four Focus Group Discussions (FGDs). After analyzing the experts' opinions and the content of the included articles, 22 codes, 8 categories, and 23 subcategories were extracted. The main categories were information access, travel time, distance to home, bureaucratic practices, transportation, rehabilitation services provision, financial problems, insurance, and family support. In the item generation step, a list of 34 items was generated, and a first draft of the questionnaire was prepared using the results of the content and literature review.

\section{Phase 2: Validity of the Questionnaire}

\section{Face Validity}

\section{Content validity}

In the content validation process, the feedbacks of the experts $(\mathrm{N}=15)$ on the relevance, simplicity, and clarity of the items were collected. Based on the experts' views, 9 items were determined as irrelevant, so they were eliminated, and 25 items remained in the questionnaire. The acceptable items were resent to the experts, and they were asked to score the relevance, simplicity, and clarity of each question.

The Cohen's kappa coefficient for the experts' agreement upon the relevance of the remained 25 items was calculated to be 0.91 . All the rehabilitation experts gave their feedback on the relevance, simplicity, and clarity of the 25 questions (response rate $=100 \%$ ). The content validity of the questionnaire was measured to be 0.91 using S-CVI/Ave approach.

\section{Phase 3: Reliability of the questionnaire}

The Cronbach alpha, McDonald's Omega, and Theta alpha for the $\mathrm{f} 4$ loaded factors were greater than 0.7 (Table 4).

Phase 4: Exploratory factor analysis

Among the participants, 117 subjects (58.5\%) were female, and 119 subjects (59.5\%) were single. Other information is presented in Table 2. The sampling adequacy index "Kaiser-Meyer-Olkin (KMO)" was 0.872, and the Bartlett test result was $1575.692(\mathrm{P}<0.001)$. Overall, four factors, namely affordability, transport, social support, and information, which accounted for $81 \%$ of the total variance (Table 3 ), were extracted using exploratory factor analysis.

\section{Discussion}

The results of this study confirmed the high content validity of the items and that of the whole questionnaire. According to the I-CVI, each question had good content validity. The average CVI approach indicated excellent content validity for the whole questionnaire.

According to the factor analysis, the items of the questionnaire were loaded on 4 factors. The first factor was the costeffectiveness. This is especially important in low-income groups since service providers may be reluctant to provide the services demanded at minimum cost, thereby the clients will fail to receive the required services [22, 23]. In 2015, the World Health Organization considered economic factors as one of the influencing factors in accessing physical rehabilitation services and emphasized that cost-effective rehabilitation services are very significant in improving the accessibility for people with disabilities [5]. The question of "How many times have you been deprived of rehabilitation services because you could not afford to pay for the drug?" has the highest factor load of 0.93 . 
The second factor in accessing to physical rehabilitation services was transport, and all responses have emphasized this parameter. The question of "How much are you compelled to seek these services because most centers are far from your home?" got the highest factor load of 0.83 .

People with disabilities often encounter considerable obstacles to access physical rehabilitation services, and transportation is an important barrier to this end [3]. In previous studies, the impact of moving people with disabilities from one place to another to avail them of health and rehabilitation services has been investigated in various forms. Failure in paying attention to this factor would result in serious adverse effects on accessing health and rehabilitation services [24-27].

The third factor was social support. In this category, the highest factor load (0.91) belonged to the question of "How much have you been deprived of rehabilitation services due to the lack of financial support from family and friends?" Social support includes disability support systems that help and encourage people with physical and mental disabilities to cope with their problems. Informal social support is usually provided by friends and relatives while formal support is provided by social organizations and social support groups [28]. Other studies have also confirmed that social support could highly affect access to health and rehabilitation services for people with disabilities [8, 29].

The fourth factor was the ability to access information associated with physical rehabilitation services. In this category, the highest factor load $(0.89)$ belonged to the question of "How much information regarding rehabilitation services has been provided to you by the rehabilitation therapists?" Lack of information access is one of the most important obstacles to accessing health and rehabilitation services. Information is not limited to a particular medium; it can even be obtained from a simple educational pamphlet provided by a health center, which can enable any person to access various technologies and gradually eliminate all information barriers worldwide [30]. Other studies have also confirmed that information access contributes to people with disabilities accessing health and rehabilitation care services. A study conducted by Timothy in 2015 on increasing access to physical rehabilitation services in hospitals and providing health education after patients' discharge from the intensive care units confirmed that providing information could increase the level of accessibility and satisfaction of the target population [26]. In 2016, a qualitative study conducted by Sousa et al., which examined the accessibility of physical rehabilitation services for the victims of road accidents, showed that the role of information is directly related to access to healthcare services [31].

\section{Conclusion}

This study was conducted to develop and validate a local questionnaire. Local and foreign researchers can use this questionnaire for assessing the accessibility of health services. Also, this questionnaire can provide policymakers, executive directors, therapists, and researchers with important insights into and accurate information on the accessibility of physical rehabilitation services for people with disabilities and enable policymakers and the like to develop effective intervention programs.

The limitations of the present study are first the incomprehensible or inaccurate responses to the questionnaire by the participants and, second and more importantly, lack of access to enough sample size.

\section{Ethical Considerations}

\section{Compliance with ethical guidelines}

The protocol of the present study was approved by the Ethics Committee of the University of Social Welfare and Rehabilitation Sciences (Code: 1393227).

\section{Funding}

This research did not receive any grant from funding agencies in the public, commercial, or non-profit sectors.

\section{Authors' contributions}

All authors contributed in preparing this article.

\section{Conflict of interest}

The authors declared no conflict of interest.

\section{Acknowledgments}

The authors would like to express their gratitude to the Campaign Officials, staff, and people with disabilities who participated in this study. 


\section{References}

[1] World Health Organization. Research for universal health coverage: World health report 2013 [Internet]. 2013 [Updated 2013 Aug]. Available from: http://www.who.int/ whr/2013/report/en/

[2] Shirazikhah M, Mirabzadeh A, Sajadi H, Joghataei MT, Biglarian A, Mousavi T, et al. National survey of availability of physical rehabilitation services in Iran: A mixed methods study. Electronic Physician. 2017; 9(11):5778-86. [DOI:10.19082/5778] [PMID] [PMCID]

[3] World Health Organization. WHO global disability action plan 2014-2021: Better health for all people with disability [Internet]. 2015 [Updated 2015 Nov 30]. Available from: https:/ / www.who.int/publications/i/item/who-global-disabilityaction-plan-2014-2021

[4] Ahmadzadeh N, Ebadi Fard Azar F, Baradaran HR, Salman Roghani R, Shirazikhah M, Joghataei MT, et al. Availability of outpatient rehabilitation facilities in 2015 in Iran: A nationwide study. Medical Journal of The Islamic Republic of Iran. 2018; 32(1):721-6. [DOI:10.14196/mjiri.32.123] [PMID] [PMCID]

[5] Skempes D, Stucki G, Bickenbach J. Health-related rehabilitation and human rights: Analyzing states' obligations under the United Nations Convention on the rights of persons with disabilities. Archives of Physical Medicine and Rehabilitation. 2015; 96(1):163-73. [DOI:10.1016/j.apmr.2014.07.410] [PMID]

[6] World Health Organization. World report on disability [Internet]. 2011 [Updated 2011]. Available from: www.who.int/ disabilities/world_report/2011/report.pdf?ua=1

[7] van Gaans DA. The accessibility of phase 2 cardiac rehabilitation programs in rural and remote Australia [PhD. thesis]. Adelaide SA: The University of Adelaide; 2013. https:// www.nintione.com.au/resources/rao/the-accessibility-ofphase-2-cardiac-rehabilitation-programs-in-rural-and-remote-australia/

[8] Shrestha J. Evaluation of access to primary healthcare. A case study of Yogyakarta, Indonesia [MSc. thesis]. Enschede: International Institute for Geo-Information Science and Earth Observation; 2010. https://webapps.itc.utwente.nl/librarywww/papers_2010/msc/upm/shrestha.pdf

[9] Pogge T. Access to medicines. Public Health Ethics. 2008; 1(2):73-82. [DOI:10.1093/phe/phn023]

[10] Stevens JP. Applied multivariate statistics for the social sciences. New York: Routledge; 2012. https://books.google. com/books?id=oIeDhzDebKwC\&dq

[11] Pilling S, Whittington C, Taylor C, Kendrick T, Guideline Development Group. Identification and care pathways for common mental health disorders: Summary of NICE guidance. BMJ. 2011; 342:d2868. [DOI:10.1136/bmj.d2868] [PMID]

[12] Gillham B. Developing a questionnaire. $2^{\text {nd }}$ ed. London: A\&C Black; 2008. https://books.google.com/ books?id=EpKvAwAAQBAJ\&dq

[13] Tilden VP, Nelson CA, May BA. Use of qualitative methods to enhance content validity. Nursing Research. 1990; 39(3):172-5. [DOI:10.1097/00006199-199005000-00015]

[14] Waltz CF, Strickland OL, Lenz ER. Measurement in nursing and health research. New York: Springer Pub- lishing Company; 2010. https://books.google.com/ books?id=1xAdjkR14ocC\&dq

[15] Polit DF, Beck CT, Owen SV. Is the CVI an acceptable indicator of content validity? Appraisal and recommendations. Research in Nursing \& Health. 2007; 30(4):459-67. [DOI:10.1002/nur.20199] [PMID]

[16] Fok D. Development and testing of a Low Vision Product Selection Instrument (LV-PSI): A mixed-methods approach [PhD. thesis]. London, Ontario, Canada: The University of Western Ontario; 2011. https://ir.lib.uwo.ca/etd/127/

[17] Soleimani MA, Pahlevan Sharif S, Allen KA, Yaghoobzadeh A, Sharif Nia H, Gorgulu O. Psychometric properties of the Persian version of spiritual well-being scale in patients with acute myocardial infarction. Journal of Religion and Health. 2017; 56(6):1981-97. [DOI:10.1007/s10943-016-0305-9] [PMID] [PMCID]

[18] Munro BH. Statistical methods for health care research Philadelphia: Lippincott Williams \& Wilkins; 2005. https:// books.google.com/books?id=a34z_Ah2-LgC\&dq

[19] Javali SB, Gudaganavar NV, Raj SM. Effect of varying sample size in estimation of coefficients of internal consistency. WebmedCentral BIOSTATISTICS. 2011; 2(2):WMC001649. http://www.webmedcentral.com/article_view/1572

[20] Mayers A. Introduction to statistics and SPSS in psychology. London, UK: Pearson; 2013. https:/ / books.google.com/ books?id=SDHtMgEACAAJ\&dq

[21] Esposito Vinzi V, Chin WW, Henseler J, Wang H. Handbook of partial least squares: Concepts, methods and applications. New York City: Springer; 2010. https:/ / www.springer. com/gp/book/9783540328254

[22] World Health Organization. Universal health coverage: Supporting country needs [Internet]. 2012 [Updated 2012 May]. Available from: http://www.who.int/contracting/ UHC_Country_Support.pdf

[23] World Health Organization. PPHC-KN Programme nodes phase 1: Analysis of conditions [Internet]. 2007 [Updated 2007 Aug 29]. Available from: https://www.who.int/social_determinants/media/pphc_phase1_guide_analysis.pdf?ua=1

[24] Amer Sh. Towards spatial justice in urban health services planning: A spatial-analytic GIS-based approach using Dar es Salaam, Tanzania as a case study [PhD. thesis]. Utrecht: University of Utrecht; 2007. http:// dspace.library.uu.nl/handle/1874/19334

[25] Aoun N, Matsuda H, Sekiyama M. Geographical accessibility to healthcare and malnutrition in Rwanda. Social Science \& Medicine. 2015; 130:135-45. [DOI:10.1016/j.socscimed.2015.02.004] [PMID]

[26] Fuchsia Howard A, Smillie K, Turnbull K, Zirul C, Munroe $\mathrm{D}$, Ward A, et al. Access to medical and supportive care for rural and remote cancer survivors in northern British Columbia. The Journal of Rural Health. 2014; 30(3):311-21. [DOI:10.1111/jrh.12064] [PMID]

[27] Obrist B, Iteba N, Lengeler C, Makemba A, Mshana C, Nathan $R$, et al. Access to health care in contexts of livelihood insecurity: A framework for analysis and action. PLoS Medicine. 2007; 4(10):1584-8. [DOI:10.1371/journal.pmed.0040308] [PMID] [PMCID] 
[28] National Center for Biotechnology Information. Social support [Internet]. 2017 [Updated 2017]. Available from: https:// www.ncbi.nlm.nih.gov/mesh/68012944

[29] van Hees S, Cornielje H, Wagle P, Veldman E. Disability inclusion in primary health care in Nepal: An explorative study of perceived barriers to access governmental health services. Asia Pacific Disability Rehabilitation Journal. 2014; 25(4):99-118. [DOI:10.5463/dcid.v25i4.373]

[30] UNESCO. Media sensitization workshop in Pakistan Handbook for decision makers access to information and knowledge platforms for persons with disabilities. In: United Nations Educational Scientific and Cultural Organization, editor. Digital Empowerment: Access to Information and Knowledge Using ICTs for Persons With Disabilities. Paris Communication and Information Sector: Knowledge Societies Division; 2016. https:/ / unesdoc.unesco.org/ark:/48223/ pf0000244543

[31] de Meneses Sousa K, de Oliveira WIF, de Melo LOM, Alves EA, Piuvezam G, da Silva Gama ZA. A qualitative study analyzing access to physical rehabilitation for traffic accident victims with severe disability in Brazil. Disability and Rehabilitation. 2017; 39(6):568-77. [DOI:10.3109/09638288.2016.115 2606] [PMID] 
This Page Intentionally Left Blank 